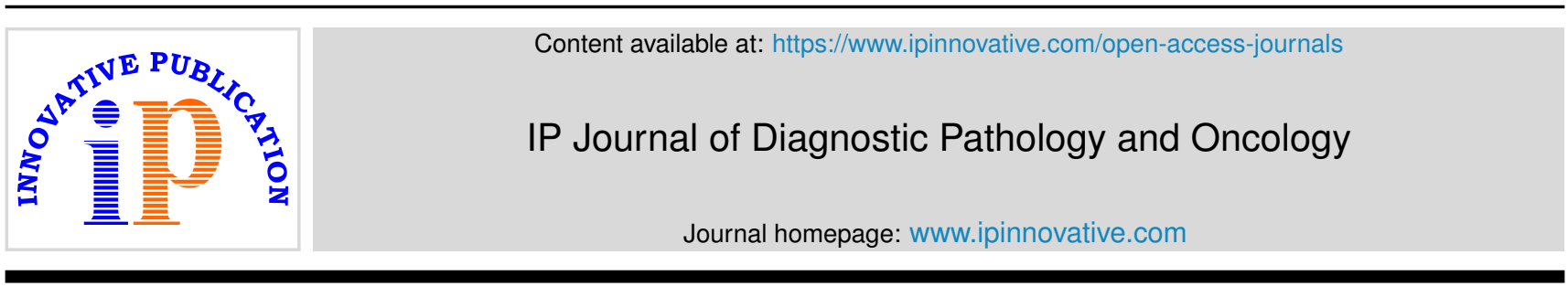

Original Research Article

\title{
Utilization of blood and blood products in a tertiary care hospital- A descriptive cohort study
}

\author{
Reena Sharma ${ }^{1}$, Madhvi Sanwalka1,* \\ ${ }^{1}$ Dept. of Pathology, National Institute Medical Science, Jaipur, Rajasthan, India
}

\section{A R T I C L E I N F O}

Article history:

Received 18-07-2020

Accepted 23-07-2020

Available online 03-09-2020

\section{Keywords:}

Packed red blood cells

Whole blood

Blood components

FFP

Wards

\begin{abstract}
A B S T R A C T
Introduction: Blood is a specialized bodily fluid that delivers necessary substances to the body's cells, such as oxygen and nutrients and transports waste products away from these cells. It is composed of cells (red blood cells, white blood cells and platelets) and plasma. Till date no substitute of blood is formed therefore transfusion of donated blood is the mainstay of treatment in medical or surgical conditions. Blood must be transfused while keeping precautions because, blood and its components can cause side effects in recipient such as transfusion reactions or transmission of transfusion transmissible disease like $\mathrm{HbsAg}$, HCV, HIV, Syphilis and malaria. It is very important for clinicians to be aware of these potential risks and hence blood should be transfused in conditions where it is needed only. This study aims to evaluate the pattern of blood component usage, its demand and utilization in a tertiary care hospital.

Materials and Methods: This is a retrospective cohort study in which data concerning request and utilization of blood and its products from January 2019 to December 2019 in blood bank of tertiary care hospital were collected and analyzed.

Results: The blood units issued were 5190. Packed red blood cell was the most utilized product. Supply of blood was maximum to the surgical wards followed by medicine ward. The patients of anemia followed by surgery required packed red blood cells mostly. Most common indication for blood products was anemia.

Conclusions: Periodic review of blood component usage is important to assess the utilization pattern of blood in any hospital.
\end{abstract}

(C) 2020 Published by Innovative Publication. This is an open access article under the CC BY-NC license (https://creativecommons.org/licenses/by-nc/4.0/)

\section{Introduction}

Blood is a specialized bodily fluid that delivers necessary substances to the body's cells, such as oxygen and nutrients and transports waste products away from these cells. It is composed of cells (red blood cells, white blood cells and platelets) and plasma. Plasma contains coagulation factors. ${ }^{1-8}$ Blood must be collected into sterile, single use, FDA licensed containers. ${ }^{1}$ The blood should be drawn from an area which is free of any skin lesions, and the phlebotomy site should be decontaminated properly. The site is scrubbed with a soap solution, followed by the application of tincture of iodine or iodophor complex solution. The selection of the venipuncture site and its decontamination is an important

\footnotetext{
* Corresponding author.

E-mail address: madhvisanwalka00@gmail.com (M. Sanwalka).
}

step in preventing bacterial contamination which is a fatal blood transfusion reaction. Till date no substitute of blood is formed therefore transfusion of donated blood is the mainstay of treatment in medical or surgical conditions. In 1818 James Blundell first performed blood transfusion successfully. ${ }^{2}$ Blood component therapy has gained interest in recent years as it is better than whole blood transfusion because it reduces volume overload in patients, has greater shelf life and better patient management. ${ }^{3}$ In between 1950-1960 blood component therapy was introduced, to maximize the benefits of all components present in the whole blood. ${ }^{8-16}$ In developing countries it is essential to make an efficient use of blood as there are limited resources of blood and increase demand in community. ${ }^{11}$ Data on the use of blood products are limited and studies have revealed that in both developing and developed countries there is high 
proportion of inappropriate use of blood transfusion. ${ }^{3}$ Blood must be transfused while keeping precautions because, blood and its components can cause side effects in recipient such as transfusion reactions or transmission of transfusion transmissible disease like HbsAg, HCV, HIV, Syphilis and malaria. It is very important for clinicians to be aware of these potential risks and hence blood should be transfused in conditions where it is needed only. This study aims to evaluate the pattern of blood component usage, its demand and utilization in a tertiary care hospital.

\section{Materials and Methods}

This is a retrospective cohort study in which data concerning request and utilization of blood and its products from January 2019 to December 2019 in blood bank of tertiary care hospital were collected and analyzed. Data of monthly requirement and its utilization was collected from record books of blood bank. It included cross matched and issue units of blood and its products. We also studied utilization of blood and its products in various department of hospital including surgery, gynecology, orthopedics, ENT and other nonsurgical departments like medicine, nephrology, neurology etc. Data also included gender of transfusion recipient. The data so obtained was fed into Microsoft excel sheet for further analysis.

\section{Results}

The total number of whole blood and its products issued from our blood bank in 1 year (1st January 2019 to 31st December 2019) was 5190 units; with a monthly average of 432 units. The supply showed some seasonal variation, with lesser units supplied near year beginning and peak observed around end of the year (Table 2).

Most common blood group for which blood was issued was A positive ( $n=816$ units) and least were of $A B$ negative ( $\mathrm{n}=40$ units) (Table 3 ).

A breakup of the supply for whole blood and various components $(\mathrm{n}=5190)$ showed that packed red blood cells $(\mathrm{n}=2740)$ was the maximum utilized product followed by fresh frozen plasma (FFP) and platelet concentrates than whole blood (Table 1). Supply of blood was found to be more in the surgical wards forming $21.49 \%$ of total supply followed by general medicine $(20.44 \%)$.

Male: female ratio of the patients was $1.3: 1$. The most common diagnosis for patients requiring blood products was anemia (43.80\%); followed by surgery $(25.55 \%)$ and trauma $(17.88 \%)$ (Table 6). The total demands for whole blood were 390 out of 5190 cases.

Males $(56.64 \%)$ consumed more blood components than female $(43.35 \%)$. Male:female ratio is 1.3:1.

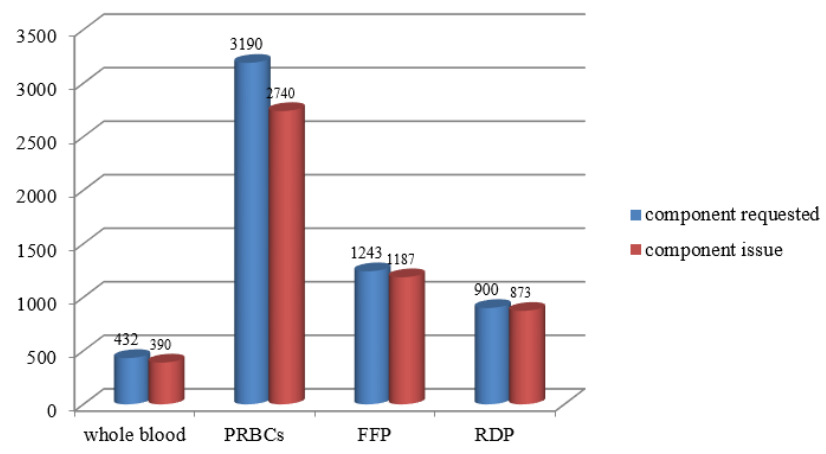

Fig. 1: Blood component distribution

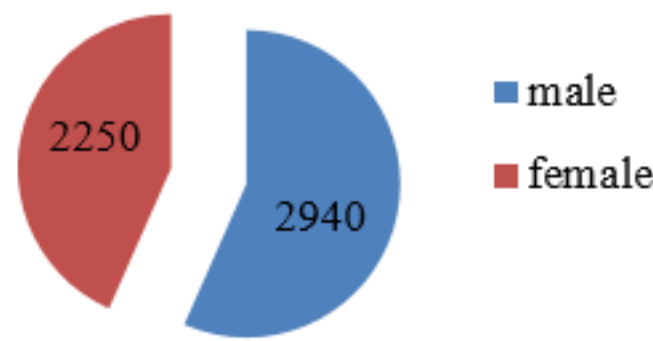

Fig. 2: Comparison of utilized blood component between male and females

\section{Discussion}

Blood transfusion is an integral part of health services. Even today clinician demand for whole blood which should be discouraged as effective use of blood with minimal wastage should be the goal so that those who are need can get blood. ${ }^{15,16}$

In the present study we received 5765 requests and 5190 units were issued after proper cross matching and screening. In our study males received more blood transfusion units than female, this is similar to the studies done by Mathew et al, ${ }^{2}$ Bansod et al. ${ }^{17}$ We noted 390 units of whole blood utilized among total 5190 blood units which is contrary to Joshi et al. who found increased number of whole blood utilization compared to other components. Anshoo et al. ${ }^{18}$ and Venkatachalapathy and Subhashish ${ }^{3}$ also found similar results as our study which showed increased utilization of packed red cells among blood components. But Ambroise et al. ${ }^{4}$ showed increased issue of FFP and Platelets in relation to PRBC. Ahmaed and Save ${ }^{19}$ noted increased utilization of PRBC $(74.9 \%)$ among paediatric patients while Venkatachalapathy and Subhashish noted highest utilization of blood units by gynaecologic department. In the present study, majority of the blood units were issued to general surgery department which constituted 589 units among total 5190 units. This was followed by medicine 
Table 1: Blood component wise distribution

\begin{tabular}{ccccccc} 
S.No & Blood component & Whole blood & PRBC & FFP & RDP & Total \\
1 & Component required & 432 & 3190 & 1243 & 900 & 5765 \\
2 & Component issue & 390 & 2740 & 1187 & 873 & 5190 \\
\hline
\end{tabular}

Table 2: Utilization of blood and blood products in one year

\begin{tabular}{|c|c|c|c|c|c|}
\hline Month & Whole blood & PRBCs & FFP & RDP & Total \\
\hline January & 33 & 162 & 92 & 28 & 315 \\
\hline February & 24 & 182 & 62 & 10 & 278 \\
\hline March & 34 & 123 & 65 & 15 & 237 \\
\hline April & 22 & 231 & 92 & 58 & 403 \\
\hline May & 23 & 290 & 115 & 67 & 495 \\
\hline June & 30 & 255 & 106 & 62 & 453 \\
\hline July & 42 & 250 & 101 & 66 & 459 \\
\hline August & 35 & 260 & 142 & 94 & 531 \\
\hline September & 36 & 232 & 91 & 89 & 448 \\
\hline October & 42 & 359 & 112 & 178 & 691 \\
\hline November & 37 & 191 & 87 & 135 & 450 \\
\hline December & 32 & 205 & 122 & 71 & 430 \\
\hline
\end{tabular}

Table 3: Comparison of most utilized blood (PRBCs) according to blood group

$\begin{array}{ccc}\text { S.No } & \text { Type of blood group } & \text { Utilization of blood (PRBCs) } \\ 1 & \text { A+ve } & 816 \\ 2 & \text { B+ve } & 780 \\ 3 & \text { O+ve } & 508 \\ 4 & \text { AB+ve } & 447 \\ 5 & \text { A-ve } & 55 \\ 6 & \text { B-ve } & 42 \\ 7 & \text { O-ve } & 52 \\ 8 & \text { AB-ve } & 40 \\ \text { Total } & & \mathbf{2 7 4 0}\end{array}$

Table 4: Comparison of various wards for blood utilization

\begin{tabular}{|c|c|c|c|c|c|}
\hline S.No & Various wards & PRBCs $(n=2740)$ & $\begin{array}{l}\text { Most utilized blood } \\
\text { product (PRBCs) \% }\end{array}$ & $\operatorname{FFP}(n=1187)$ & $\operatorname{RDP}(n=873)$ \\
\hline 1 & General surgery & 589 & 21.49 & 226 & 145 \\
\hline 2 & Trauma centre & 490 & 17.88 & 129 & 56 \\
\hline 3 & Orthopedics & 301 & 10.98 & 167 & 134 \\
\hline 4 & Neurosurgery & 100 & 3.66 & 34 & 22 \\
\hline 5 & Gynecology & 155 & 5.67 & 55 & 65 \\
\hline 6 & Otolaryngology & 120 & 4.38 & 19 & 34 \\
\hline 8 & Cardiothoracic surgery & 150 & 5.47 & 154 & 78 \\
\hline 9 & General medicine & 560 & 20.44 & 201 & 265 \\
\hline 10 & Nephrology & 43 & 1.55 & 46 & 23 \\
\hline 11 & Pediatrics & 32 & 1.18 & 65 & 12 \\
\hline 12 & Others & 200 & 7.30 & 101 & 39 \\
\hline
\end{tabular}

Table 5: Comparison between various diseases for most utilization of blood (PRBCs=2740)

\begin{tabular}{cccc}
\hline S.No & Various disease & Blood utilized(units) & $\%$ \\
1 & Anaemia & 1200 & 43.80 \\
2 & RTA & 490 & 17.88 \\
3 & Pregnancy & 20 & 0.73 \\
4 & Post operative & 300 & 10.95 \\
5 & Emergency & 30 & 1.09 \\
6 & surgery & 700 & 25.55 \\
\hline
\end{tabular}


Table 6: Various disease of utilization of FFP and RDP

$\begin{array}{cccc}\text { Disease } & \text { FFP }(\mathbf{n}=\mathbf{1 1 8 7}) & \text { RDP }(\mathbf{n = 8 7 3}) & \text { WB }(\mathbf{n}=\mathbf{3 9 0}) \\ \text { Anaemia } & 34 & 12 & 102 \\ \text { Trauma } & 313 & 373 & 78 \\ \text { Labour/child birth } & 121 & 56 & 32 \\ \text { Surgery } & 442 & 182 & 45 \\ \text { Postoperative } & 232 & 124 & 43 \\ \text { Emergency } & 45 & 126 & 90\end{array}$

It is shown that FFP and RDP are used mostly in surgeries.

and trauma which showed nearly equal distribution of blood units (560 and 490 respectively). The majority of the blood requested was a positive for both females and males. For PRBC as well as other blood components most common indication was Anemia. In studies conducted by Babita et al., Subham et al., Mathew et $\mathrm{al}^{2}$ and Bansod et al. ${ }^{18}$ majority of females had transfused blood which is contrary to our study. In studies conducted by Subham et al, Dushyanth et al, ${ }^{20}$ Girian S S et al. ${ }^{21}$ and Joshi et al. ${ }^{22}$ showed that whole blood was most common used blood component which was contrary to our study. Alcantara et al $^{16}$ found medicine department utilizing maximum number of blood units. Study conducted by Subham et al showed that the most common indication for whole blood and PRBC was Anemia which is similar to our study.

Whole blood and its components are considered as drugs by the Food and Drug Administration (FDA) as its use produce therapeautic benefits to the patient. Thus FDA emphasizes on the quality of blood and its products and apply various standards to the collection, testing, storage and supply of safe blood. Indications for blood usage have been changed with time. In the post-World War II era, blood transfusion indication was a $\mathrm{Hb}$ level less that $10 \mathrm{~g} / \mathrm{dl}$. Presently, better guidelines have been suggested according to the specific need of patient. It is now a standard practice of blood bank to manufacture different blood components from donated whole blood units and supply only specific components thereafter to patients which they need. ${ }^{23-26}$ However, use of whole blood is recommended in certain situations, One such situation is polytrauma, as in road accident casualties and hypovolemia (class III and IV). Whole blood is needed in an actively bleeding case with loss of more that $25 \%$ of total blood volume or an active bleeding patient who has already received 4 units of PRBC, as it not only replenishes the blood volume and oxygencarrying capacity, but also prevents dilution of coagulation factors too.

It is very important to consider that in cases of anemia the values of $\mathrm{Hb}$ and hematocrit is important to note before blood tranfusion and correlate the clinical condition of the patient. ${ }^{27}$ Misuse of PRBC can also be avoided in patients whose $\mathrm{Hb}$ or hematocrit can be improved by other means like diet, hematinics, etc. Clinicians often transfuse 1 or 2 units of blood to moretate to-severely anemic patients, which actually brings no benefit to these patient as it does not increase the $\mathrm{Hb}$ or oxygen carrying capacity significantly but introduces several foreign antigens in the blood circulation of the recipient. Similarly in cases of shock, sometimes blood is transfused in class I and II, where it is not recommended according to WHO guidelines. Cases where there is established hypovolemia of class II and above and showing only transient or no improvement need to be transfused blood. ${ }^{28,29}$ In the case of FFP, it is recommended to transfuse 5-6 units to correct the hemostatic defect which is due to clotting factor deficiency. ${ }^{24}$

In surgical cases blood and blood components are often ordered more than needed due to anticipated loss than actual one. This practice, to hold a ration of cross matched blood for operative cases in advance to combat any unforeseen complications during or after operation is not good as often this blood is not used and causes wastage of blood. for such situation in which there is an anticipation of use of blood a better option would be to keep a reserve of blood in the Blood bank itself and not in the ward, which can be supplied to the patient on demand and if not utilized, can be used for other patients who is in need. Thus inappropriate use of blood should be avoided.

Over the last two decade use of platelet is increased due to its ready availability, which helps in managing acute hematological and malignancy conditions. ${ }^{17}$

Autologous transfusions importance should be emphasized to ensure availability of patient's own blood which is most effective and immunologically safe for him.

\section{Conclusion}

This study gives information on blood component usage in our tertiary care hospital. It demonstrates the trend of utilization of blood and blood components, cost analyses Packed red blood cell (PRBCs) was the maximum utilized product followed by FFP, platelet concentrates and then least is whole blood. Supply of blood was found to be highest in the surgical wards. The most common diagnosis of patients requiring blood was anemia followed by surgery. Overall, anemia was the most common indication. Packed red blood cell is used in plenty at our center as it caters to a large number of anemia cases. 
Periodic assessment of blood usage followed by educational sessions for clinicians is recommended to prevent its overuse or misuse, which may lead to shortage of blood to someone in a life-threatening situation as blood demand is high than its supply. Our study has limitations because our data is derived from a single center and represents only a small proportion of the North India population. Well-designed national studies are essential to formulate guidelines to improve transfusion practices and understand the variation in transfusion practices in India.

\section{Source of Funding}

None.

\section{Conflict of Interest}

None.

\section{References}

1. Rubin RJ, Ness PM. What price progress? An update on vinyl plastic bags. Transfus. 1989;29(4):358-61.

2. Mathew AS, Kurian SS, Sundaresan NP, Jayalekshmi, Roderigues FP. Pattern of blood component utilization in a teaching hospital in South Kerala. Acad Med J India. 2014;2:28-31.

3. Venkatachalapathy TS, Subhashish D. A Prospective audit of blood transfusion request in RL Jalappa Hospital and research centre for blood and blood components. J Blood Lymph. 2012;2:106.

4. Ambroise M, Ravichandran K, Ramdas A, Sekhar G. A study of blood utilization in a tertiary care hospital in South India. J Nat Sci, Biol Med. 2015;6(1):106-10.

5. Chowdhury FS, Siddiqui A, Islam K. Use of blood and blood components in. Dhaka Med Coll Hospital. 2015;26:18-24.

6. Alcanatara YT, Shammary A, S. a comparative study on Blood components utilization in selected Hospital- blood banks in hali. KSA IOSR J Nursi Health Sci. 2015;4:28-33.

7. Pozo EA, Rosales PM, Cd AN, Remesar MC, Cortes AD. A comprehensive protocol to evaluate the use of blood and its components in Latin America and the Caribbean. Rev Panam Salud Publica. 2015;37:435-441.

8. Bansod P, Jethani N, Pachori G. Clinical use of blood and its components in tertiary health care center in northwestern India. Int J Med Sci Public Health. 2015;4(6):787-91.

9. Garg R. an audit of the blood and component transfusion requests and utilization pattern in a tertiary care hospital-current trends. Int J Drug Discov Med Res. 2013;1:82-5.

10. Varghese R, Gomathi G. Audit of use of blood and its components in a tertiary care center in South India. Asian J Transfus Sci. 2012;6(2):189-90.

11. Ahmad M, Save US. Blood components therapy in pediatric intensive care unit in tertiary care centre: an audit. Int J Contemp Med Res. 2016;3:1506-10.
12. Wa B, Aziz R, Ahmed CB, Ahmed IS. Utility of blood components in Pediatric patients. An Audit. 2012;16:61-3.

13. Anshoo A, Saidunnisa B, Meghana C, Emadullah R. Where does blood go? Study on transfusion practice in SAQR hospital. Int $J$ Sci Res. 2013;2:56-9.

14. WHO. Guidelines and Principles for safe blood transfusion practices; 2009.

15. Mackroo RN. Transfusion Practice In Clincal Medicine. Compendium Transfus Med. 2009;p. 217-8.

16. Alcantara J, Opiña A, Alcantara R. Appropriateness of Use of Blood Products in Tertiary Hospitals. Int Blood Res Rev. 2015;3(2):54-65.

17. Wallace EL, Surgenor DM, Hao HS, An J, Chapman RH, Churchill $\mathrm{WH}$, et al. Collection and transfusion of blood and blood components in the United States, 1989. Transfus. 1998;38:625-36.

18. Anshoo A, Saidunnisa B, Meghna C, Emadullah R. Where does blood go? Study on transfusion practices in SAQR hospital. Int J Sci Res. 2013;2:56-9.

19. Ahmed M, Save US. Blood components Therapy in paediatric intensive care unit in tertiary care centre: An audit. Int J Contemp Med Res. 2016;3:1506-10.

20. Gaur DS, Negi G, Chauhan N, Kusum A, Khan S, Pathak VP, et al. Utilization of blood and components in a tertiary care hospital. Indian J Hematol Blood Transfus. 2009;25(3):91-5.

21. Giriyan SS, Chethana HD, Sindhushree N, Agarwal A, Nirala NK, Bajpai R, et al. Study of Utilization of Blood and Blood Components in a Tertiary Care Hospital. J Blood Lymph. 2017;07(02):1-3.

22. Joshi GP. Audit in transfusion practice. J Eval Clin Pract. 1998;19:141-6.

23. Hawkins TE, Carter JM, Hunter PM. Can mandatory pretransfusion approval programmes be improved? Transfus Med. 1994;4(1):45-50.

24. Greeno E, McCullough J, Weisdorf D. Platelet utilization and the transfusion trigger: a prospective analysis. Transfus. 2007;47(2):2015 .

25. Zimmermann R, Buscher M, Linhardt C, Handtrack D, Zingsem J, Weisbach V, et al. A survey of blood component use in a German university hospital. Transfus. 1997;37(10):1075-83.

26. Harmening DM. Modern Blood Banking and transfusion practices. FA Davis Company Philadelphia; 1998.

27. Stanworth SJ, Cockburn HAC, Boralessa H, Contreras M. Which groups of patients are transfused? A study of red cell usage in London and southeast England. Vox Sang. 2002;83(4):352-7.

28. Harmening DM. Modern Blood Banking and transfusion practices. FA Davis Company Philadelphia; 1998.

29. 31.World Health Organization. The clinical use of blood in medicine, obstetrics, paediatrics, surgery \& anesthesiology. 2001;

\section{Author biography}

Reema Sharma Assistant Professor

Madhvi Sanwalka Junior Resident

Cite this article: Sharma R, Sanwalka M. Utilization of blood and blood products in a tertiary care hospital- A descriptive cohort study. IP J Diagn Pathol Oncol 2020;5(3):313-317. 